\title{
Managing Risks and Exposures to Silica in Training and Assessment Activities in Vocational Education and Training
}

\author{
Richard Skiba \\ LRES Training Management, Melbourne, Australia
}

Tel: 614-04-043-013 E-mail: richard@skiba.com.au

Received: May 7, 2020 Accepted: June 8, 2020 Published: June 25, 2020

doi:10.5296/ijld.v10i2.16989 URL: https://doi.org/10.5296/ijld.v10i2.16989

\begin{abstract}
A number of activities in workplaces, such as such as those including cutting, grinding, sanding, drilling, loading or demolishing products that contain silica, can produce respirable particles of crystalline silica dust that are small enough to inhale. Inhalation of crystalline silica can cause silicosis which is incurable. Work practices are critical to prevent the condition from occurring and safe work practices are as relevant to workplaces as they are to training environments. This study considers methods of risk control and training practices such that silicosis is prevented.

Training requirements are profiled in a vocational education and training setting and must include: crystalline silica hazards and health risks, including silicosis; effective use controls; use and maintenance of personal protective equipment, including Respiratory Protective Equipment; safe waste disposal; and, practices for personal decontamination. The training environment must be designed in a manner to allow for engineering controls, such as on-tool water suppression or on-tool dust extraction, to be utilised.
\end{abstract}

Keywords: Silicosis, health and safety, vocational education and training, managing risk, training practices 


\section{Introduction}

In February, 2020, Safe Work Australia (2020b) advised that under the model Workplace Health and Safety (WHS) Regulations, a Person Conducting a Business or Undertaking (PCBU) must provide health monitoring for workers where those workers perform ongoing work using, handling, generating or storing crystalline silica, and there is a substantial risk to the worker's health because of exposure. Health monitoring for crystalline silica seeks to protect workers whose health may be at risk. Trainers and Assessor who train those to work with crystalline silica are required to be aware of the legislative and mandated requirements such that they can be applied and be actively promoted to all their students.

Safe Work Australia (2020a) advised that crystalline silica is found in sand, stone, concrete and mortar and materials such as soil, granite, rock, and many others. Crystalline silica is also used to manufacture a variety of products including composite stone used to fabricate kitchen and bathroom benchtops, bricks, tiles and some plastics. Engineered stone, sometimes also called reconstituted stone, contains at least 80 per cent crystalline silica (Worksafe Victoria, 2020) as it is primarily developed from naturally forming quartz. When these materials containing silica are cut, crushed, drilled, polished, sawed or grinded, dust particles are generated that are small enough to lodge deep in the lungs and cause illness or disease including silicosis. Respirable crystalline silica dust is a hazardous substance which can lead to serious health effects if it is inhaled.

Workers using these products, such as stonemasons, are at high risk of exposure to the dust if it is not controlled. This exposure, in turn, can result in silicosis, chronic bronchitis, emphysema, lung cancer, kidney damage and scleroderma. Respirable silica dust particles are small enough to penetrate deep into the lungs and can cause irreversible lung damage. Safe Work Australia (2020a) noted that the non-crystalline or amorphous forms of silica do not cause this kind of lung damage. Worksafe Victoria (2019) noted that crystalline silica dust can be harmful when it is breathed in over a long period of time at low to moderate levels, or short periods at high levels.

There are several examples of activities that can generate respirable silica dust particles (Safe Work Australia, 2020a). These include, but are not limited to: fabrication and installation of composite stone; excavation, earth moving, pit and drilling plant operations; clay and stone processing machine operations; paving and surfacing; mining, quarrying and mineral ore processing; construction and demolition activities; brick, concrete or stone cutting, particularly using dry methods; sand/abrasive blasting; foundry casting; angle grinding, jack hammering and chiseling concrete or masonry; hydraulic fracturing of gas and oil wells; and pottery making. These activities are undertaken across a broad range of industries and occupations and these activities are often integrated into manufacturing processes. As such, there are many units of competency being delivered in the Vocational Education and Training (VET) Sector that require cutting, crushing, drilling, polishing, sawing or grinding products that contain silica. Exposure can occur during training activities and assessment activities and the risks must be controlled in both cases. 


\section{Method}

A qualitative content analysis approach, as promoted by Elo and Kyngäs (2007), was adapted within this study to discuss, make interpretations and make inferences related to established practices and noted research related to workplace crystalline silica dust producing activities. This study is based on a review of relevant legislation and regulations, regulatory body publications and a literature review to provide insight, represent facts and provide practical guidance utilising an approach as advocated by Krippendorff (1980). The review determines the intentions and focus of a range of documented methods and systems related to occupational silica exposure and silicosis associated with work practices, such that these can be contextualised into training practices that can be implemented in vocational education and training settings through an exploratory approach.

Exploratory research methods provide a research design that can be useful for gaining background information on a particular topic. The approach is seen as flexible in that it can be applied to determine research questions including what, why and how to contribute original knowledge. There is also an opportunity to define new terms and clarify existing concepts and to generate formal hypotheses and develop more precise research problems. These types of studies also facilitate the establishment of research priorities for further research.

The exploratory research design is popularly characterised by literature searches, depth interviews, focus group research or case study analysis (Chinese Scholarship Council, 2020). The literature search includes the existing knowledge, review of substantive results, and text contributions to the theory and methods of a particular topic. These designs can allow the researcher to provide a deep insight into a specific subject. The method also provides for causal research where cause-and-effect relationships can be examined such that patterns of relationship can be defined.

The findings and reflections resulting from exploratory research shed new light on phenomena that have been explained in part and in different ways. The approach is, as advocated by Bernd (2017), an instrument of the expansion of knowledge, awareness, and of conceptual and intellectual expansion in social sciences, including theory and practice in Vocational Education and Training.

\section{Discussion}

\subsection{Legislative Provisions (Australia)}

In Victoria, the Occupational Health and Safety Regulations 2017 (OHS Regulations) have been amended to provide greater protection to Victorian employees working with engineered stone (Worksafe Victoria, 2020). The changes that came into effect on 20 August 2019, prohibit uncontrolled cutting, grinding and abrasive polishing of engineered stone with power tools. Through the model WHS Regulations, applicable throughout various jurisdictions in Australia, PCBUs have specific duties to manage the risks to health and safety when using, handling, generating and storing hazardous chemicals, including silica. PCBUs also have a duty to ensure the workplace exposure standard for crystalline silica is not exceeded and to provide health monitoring to workers performing tasks that produce respirable particles of 
crystalline silica dust. These duties highlight the shared responsibility for health and safety in workplaces including all stakeholders.

Safe Work Australia (2020a) outlined that the minimum health monitoring requirements for crystalline silica include: collection of demographic, medical and occupational history; completion of records of personal exposure; utilization of a standardised respiratory questionnaire; undertaking standardised respiratory function tests, such as, FEV1, FVC and FEV1/FVC, and chest X-Ray full PA view. The chest X-Ray full PA view being only required for baseline and high risk workers.

In Queensland, abrasive blasting with materials containing more than 1 per cent free crystalline silica, also referred to as sand blasting, is prohibited in workplaces (WorkCover Queensland, 2020). Rather than abrasive blasting with crystalline silica, alternative media such as garnet, crushed glass, glass bead, metal shot, aluminium oxide, granulated plastic, and some metal slags may be used (WorkCover Queensland, 2020).

\subsection{Silicosis}

Delgado and Sultan (2019, p60) advised that "silicosis is a lung disease caused by the inhalation of silica dust and the consequent depositing of this inorganic material in the bronchi, lymph nodes, and/or lung parenchyma, with or without, associated respiratory dysfunction”. They further noted that it is an irreversible disease (Delgado \& Sultan, 2019). Cancer Council (2019) described that "exposure to silica dust can lead to the development of lung cancer, silicosis, kidney disease and chronic obstructive pulmonary disease". It is estimated that 230 people develop lung cancer each year (Cancer Council, 2019) due to past exposure to silica dust at work. Work Health and Safety Queensland (2020) noted that aside from silicosis, other diseases can be caused by breathing in silica dust, including chronic bronchitis, emphysema, lung cancer, chronic kidney disease, scleroderma and rheumatoid arthritis.

Shamim, Alharbi, Pasha, and Nour (2017) explained that when the silica particles of 0.5 to 5 microns diameter are breathed into the lungs, they embed in the alveolar sacs and ducts resulting in inflammation. They state "the inflammation and scarring damage the lung sacs, prevent gas exchange, and normal breathing" and "damage to the lung tissue means that the capacity of the lungs to supply oxygen to the blood is reduced" (Shamim et al., 2017, p556).

There are 3 common types of silicosis including chronic, accelerated and acute. Chronic silicosis results from exposure to silica dust for more than 10 years, accelerated from exposure to silica dust for 3 to 10 years, and acute silicosis develops within weeks or months of exposure to silica dust (Work Health and Safety Queensland, 2020). The symptoms of silicosis may be shortness of breath, a cough, occasional chest pain, loss of appetite and tiredness and as the disease progresses the shortness of breath gets worse and can become permanent (Work Health and Safety Queensland, 2020). The symptoms become severe as the condition gets worse. Over time the cough increase in severity and persistence, the chest pain can exacerbate, weight loss can arise, and night sweats may be experienced. The damage to the lungs can not be reversed (Shamim et al., 2017) and treatment usually includes inhalers and oxygen therapy to improve breathing and quality of life. 


\subsection{Managing Risks}

All workplaces, employers and employees in Australia must comply with their workplace health and safety procedures. Workers in certain occupations are at higher risk of silicosis and these include mining, metal fabrication, building and construction including demolition, glass manufacturing, farming and civil construction. Managing risks and worker exposures to silica in these industries can be attained by selection and implementation of measures based on the hierarchy of controls (Safe Work Australia, 2020a):

- $\quad$ substitution, which can include using composite stone with a lower percentage of silica

- isolation of the hazard using principles of safe work design, including: designation of specific areas for tasks that generate dust; appropriate worker positioning during crystalline silica dust producing activities; use of enclosures and automation to conduct dust generating tasks

- engineering controls that minimise the risk of exposure to generated dust, such as use of local exhaust ventilation, water suppression (wet cutting) or using tools with dust collection attachments

- and, where a risk still remains; administrative controls, such as good housekeeping policies, shift rotations and modifying cutting sequences

- and, should a risk still remain; personal protective equipment including appropriate respiratory equipment (generally a minimum of a P2 efficiency half face respirator) and work clothing that does not collect dust.

More than one control will normally be required to adequately protect workers. Safe Work Australia (2020a) advise that the workplace exposure standard for respirable crystalline silica that must not be exceeded is $0.1 \mathrm{mg} / \mathrm{m} 3$ over an eight-hour time weighted average. PCBUs should keep worker exposures to respirable silica dust as low as reasonably practicable. Air monitoring needs to be conducted where there is any doubt that the exposure standard is being exceeded, or to identify if there is a risk to a worker's health. Delgado and Sultan (2019) concur that the application of sufficient and acceptable dust control measures in work environments allows workers to prevent or control exposures and, in turn, to avoid or limit the potential for the disease.

Johnson, Phillips, Qi, Van, and Hawley (2017) found that on-tool Local Exhaust Ventilation (LEV) and sheet-flow-wetting were effective in reducing exposures, especially when used in combination, and that this approach reduced geometric mean exposures by as much as $95 \%$. They concluded that sheet-flow-wetting combined with on-tool LEV can be an effective engineering control for the reduction of respirable dust exposures whilst working with engineered stone. When designing training programs, training providers should consider ways to apply these practices.

Exposure standards vary around the world. In USA, the Occupational Safety and Health Administration (OSHA) publicized its final rule on occupational exposure to respirable crystalline silica in March 2016 and specified a new Permissible Exposure Limit (PEL) for 
respirable crystalline silica of $50 \mu \mathrm{g} / \mathrm{m} 3$ of air calculated as an eight-hour time-weighted average. Gottesfeld (2018), after examining the occupational exposure limits in 34 countries, found that the exposure limits for quartz on an average limit of $0.1 \mathrm{mg} /$ and range from 0.025 to $0.3 \mathrm{mg} /$. Trainers must be aware of the jurisdictional occupational exposure limits applicable to them and ensure control measures are in place to meet these requirements.

Delgado and Sultan (2019) advised that a fundamental preventative measure is to raise awareness among key work environment stakeholders about the magnitude of the health problem caused by Silicosis. The vocational education and training system is well placed to raise awareness in its learners prior to them entering the workforce, or whilst re-skilling or upskilling.

\subsection{Training Environments}

In training environments silica dust must be captured or suppressed, usually with water, when working with materials containing crystalline silica. Facilities and equipment must be set up to include suppression or capture of silica dust, and in some cases, this may require replacement of equipment and development of revised processes. Water suppression should be used only with tools designed to operate in that manner. Work Health and Safety Queensland (2020) recommended the use of vacuum extraction systems with hand-held power tools and caution to ensure the vacuum or dust extractor is properly rated as "H-class for stone benchtop fabrication and installation, $\mathrm{M}$ or $\mathrm{H}$-class for general construction and $\mathrm{H}$-class for other industries". These processes stop or reduce the amount of silica dust being produced during training activities and reduce exposure for learners and trainers. Throughout training and during assessment activities, effective dust controls including on-tool water suppression or on-tool dust extraction, need to be used when these tasks are performed (Worksafe Victoria, 2019).

Learners and trainers can also be stopped from breathing in silica dust through the use of barriers to isolate others from dust producing activities. Learner and worker exposure are also reduced through the use of high-efficiency particulate air (HEPA) filtered air-conditioning systems in fixed and mobile plant operator cabins (Work Health and Safety Queensland, 2020). These are essential control mechanisms that must be implemented in all training environments to maintain health and safety requirements.

A range of practical administrative controls should also be applied. These include using a Dust Class $\mathrm{M}$ or $\mathrm{H}$ vacuum cleaner or wet methods to clean dusty floors or surfaces, rather than using dry sweeping, compressed air or high-pressure water (Worksafe Victoria, 2019). During training and assessment activities, dust should be cleaned up using low pressure water, wet mopping, wet wiping or an appropriately rated vacuum cleaner. Silica dust should be kept wet, as a slurry and cleaned up regularly to prevent it drying out. These processes should form part of the assessment requirements and should be overtly assessed whilst determining competence.

Worksafe Victoria (2019) recommended cleaning Personal Protective Equipment (PPE) after each use to ensure that dust does not accumulate, using low pressure water or wet rags. Training session plans should accommodate these activities by allowing sufficient time for 
them to occur. The required cleaning resources must also be available. Where engineering controls of risks of exposure to silica dust are inadequate, learners and trainers should use Respiratory Protective Equipment (RPE), that complies with relevant standards, such as AS/NZS 1716 - Respiratory protective devices in Australia. These should be available and in serviceable condition within the training environment. Training processes need to ensure that learners are taught to correctly fit the RPE.

Training providers should also develop a written exposure control plan that describes the tasks that could expose workers to silica dust. It should also define the engineering controls, work and environmental practices, and respiratory protection used to limit exposure for each relevant task and the measures and restricted work area procedures used to limit exposure. Learners should be made aware of the plan through their training and implement the plan in their training and assessment activities.

\section{Conclusion}

Training and Assessment systems must allow for maintenance of the minimum exposure standards and apply suitable control measures, and these should likewise be integrated into the training received by the students. Trainers should include, where they have not currently done so, specific assessment observations and collect evidence of competence in the application of the hierarchy of control in managing risks and worker exposures related to working with crystalline silica. Enforcing these safe practices is significant to a broad range of stakeholders in VET including trainers, educators, consultants, coaches, course coordinators, mentors, instructors, academics, teachers, facilitators, designers and assessors.

\section{References}

Bernd, R. (2017). Theory and Methodology of Exploratory Social Science Research. International Journal of Science and Research Methodology, 5(4), 129-150.

Cancer Council. (2019). Silica Dust. Retrieved from https://www.cancer.org.au/preventing-cancer/workplace-cancer/silica-dust.html

Chinese Scholarship Council. (2020). Exploratory Research Definition, Exploratory Research Example, Exploratory Research Question. Retrieved from https://www.chinesescholarshipcouncil.com/explanatory-research.html

Delgado, D., \& Sultan, N. (2019). Silicosis: Origins and Consequences. American Journal of Medical Sciences and Medicine, 7(3), 60-63. https://doi.org/10.12691/ajmsm-7-3-2.

Elo, S., \& Kyngäs, H. (2007). The qualitative content analysis process. Journal of Advanced Nursing, 62(1), 107-115. https://doi.org/10.1111/j.1365-2648.2007.04569.x

Gottesfeld, P. (2018). International silica standards: Countries must update exposure limits. Retrieved from https://www.ishn.com/articles/109495-international-silica-standardscountries-must-update-exposure-limits

Johnson, D. L., Phillips, M. L., Qi, C., Van, A. T., \& Hawley, D. A. (2017). Experimental Evaluation of Respirable Dust and Crystalline Silica Controls During Simulated Performance 
of Stone Countertop Fabrication Tasks With Powered Hand Tools. Annals of Work Exposures and Health, 61(6), 711-723. https://doi.org/10.1093/annweh/wxx040

Krippendorff, K. (1980). Content Analysis: An Introduction to its Methodology. Sage Publications, Newbury Park.

Safe Work Australia. (2020a). Crystalline silica and silicosis. Retrieved from https://www.safeworkaustralia.gov.au/silica

Safe Work Australia. (2020b). Health monitoring guide for crystalline silica. Retrieved from https://www.safeworkaustralia.gov.au/media-centre/news/health-monitoring-guide-crystalline -silica.

Shamim, M., Alharbi, W. D. M., Pasha, T. S., \& Nour, M. O. M. (2017). Silicosis, A Monumental Occupational Health Crisis in Rajasthan - An Epidemiological Survey. International Journal of Research-Granthalaya, 5(7), 554-583. https://doi.org/10.5281/zenodo.841120.

WorkCover Queensland. (2020). General health and safety issues. Retrieved from https://www.worksafe.qld.gov.au/injury-prevention-safety/workplace-hazards/dangers-in-you r-workplace/abrasive-blasting/general-health-and-safety-issues

Worksafe Victoria. (2019). Dust containing crystalline silica in construction work. Retrieved from https://www.worksafe.vic.gov.au/dust-containing-crystalline-silicaconstruction-work

Worksafe Victoria. (2020). Changes to protect Victorians working with engineered stone: Information about new requirements for working with engineered stone, introduced by the Occupational Health and Safety Amendment (Crystalline Silica) Regulations 2019. Retrieved from https://www.worksafe.vic.gov.au/changes-protect-victorians-workingengineered-stone

Work Health and Safety Queensland. (2020). Silica and the lung. Retrieved from https://www.worksafe.qld.gov.au/_data/assets/pdf_file/0015/83130/silica-lung-factsheet.pdf

\section{Copyright Disclaimer}

Copyright for this article is retained by the author(s), with first publication rights granted to the journal.

This is an open-access article distributed under the terms and conditions of the Creative Commons Attribution license (http://creativecommons.org/licenses/by/4.0/). 